\title{
A DIGNIDADE DA VIDA E A PROTEÇÃO DOS ANIMAIS: ANÁLISE ASSENTADA
} NOS NOVOS PARADIGMAS ECOCENTRISTAS

\author{
Maria Vital da Rocha ${ }^{1}$ \\ Lidiane Moura Lopes ${ }^{2}$
}

\section{RESUMO}

Exprime o desenvolvimento da proteção conferida aos animais pelo ordenamento jurídico pátrio, partindo de uma revisão dos antigos paradigmas calcados no antropocentrismo, revisando os posicionamentos utilitaristas que nortearam durante extensos anos a proteção do meio ambiente. Com base na doutrina nacional e estrangeira, assim como no acompanhamento do vagaroso decurso de adequação das leis aos novos valores que desenharam a própria tutela do meio ambiente na Constituição Federal de 1988, é possível analisar como as novas decisões judiciais posicionam o tratamento dos animais.

PALAVRAS-CHAVE: Ética Ambiental. Proteção dos Animais. Tutela Penal. Maus- Tratos. Dignidade da Vida.

\section{THE DIGNITY OF LIFE AND THE PROTECTION OF ANIMALS: ANALYSIS BASED ON THE NEW ECOCENTRIST PARADIGMS}

\begin{abstract}
This article aims to present the evolution of protection given to animals by the national legal system, starting from a review of the old paradigms based on anthropocentrism, reviewing the utilitarian positions that have guided the protection of the environment for many years. Based on national and foreign doctrine, as well as following the slow process of adapting the laws to the new values that designed the protection of the environment itself in the Federal Constitution of 1988 , it is possible to analyze how the new judicial decisions have positioned the treatment of animals.
\end{abstract}

KEY WORDS: Environmental ethics. Animal protection. Criminal protection. Mistreatment. Dignity of life.

\section{Introdução}

\footnotetext{
${ }^{1}$ Pós Doutoranda em Direito, na Faculdade de Direito da Universidade de Lisboa (clássica). Doutorado em Direito Civil pela Universidade de São Paulo. Professora Adjunta de Direito Civil, na Faculdade de Direito da Universidade Federal do Ceará, lecionando na graduação e no programa de pós graduação stricto sensu, é Professora Titular do Curso de Direito do Centro Universitário 7 de Setembro - UNI7, lecionando na graduação e no mestrado. Procuradora Federal aposentada. Contato: mavital@secrel.com.br.

2 Advogada. Professora Universitária no Centro Universitário Estácio do Ceará. Mestra em Direito pela Universidade Federal do Pará. Doutora em Direito e Ordem Constitucional pela Universidade Federal do Ceará UFC. Contato: lidimlopes@ hotmail.com.
} 
Desde os primórdios, a relação homem versus natureza mostrou-se conflitante, pois o primeiro sempre ousou ir além dos limites que a capacidade de produção permitia. Do mesmo modo, os animais - os denominados in anima vili - foram, durante largo período relegados a mera condição de coisas, objetos pertencentes ao patrimônio de alguém na circunstância de in anima nobili - o ser humano - cuja violência sofrida, capaz inclusive de lhes retirar a própria vida, resolvia-se com a tutela que o Direito Penal conferia ao patrimônio, configurando um dano.

A construção de alicerces mais sólidos, no entanto, com a incorporação de valores que transcenderam os antigos paradigmas antropocêntricos que fizeram do homem o centro de todas as preocupações, trouxe também novas luzes para a necessidade de uma tutela mais eficaz dos seres não humanos.

Passa-se, com efeito, de uma posição que os subjuga como meros bens, ao reconhecimento de que são seres dotados de sentimentos, sendo possível atribuir-se uma dignidade que, agora, não se limita ao ser humano, mas alcança de igual maneira os chamados seres sencientes.

Este novo modelo precisou da adaptação e acompanhamento da legislação e, neste sentido, o Direito Penal desempenhou importante papel, sendo a maneira mais efetiva de controle social, tendo-se mostrado eficaz meio de tutela dos animais. No primeiro estádio, alçou às condutas atentatórias como mera contravenção penal, passando adiante a dispor do crime de maus-tratos, tal como o concebe hoje a Lei 9.606/98.

Impunha-se, entretanto, ir além, o que foi feito com o reconhecimento, pelo Judiciário, da importância autônoma do meio ambiente, numa visão que despreza o sentido meramente utilitarista que historicamente se conferiu à matéria.

De tal sorte, a pesquisa que ora se relata por intermédio deste artigo é de caráter eminentemente exploratório e de cunho dedutivo, havendo-se utilizado, como fonte, de um levantamento bibliográfico e jurisprudencial, pretendendo estabelecer a evolução do tratamento conferido à tutela dos animais no Brasil e sua repercussão nas decisões dos tribunais.

\section{Revista dos antigos paradigmas antropocêntricos}

A lógica que permeou durante muito tempo a proteção do meio ambiente estava alicerçada na necessidade que o homem tem de autopreservação e, com suporte nela, de tutelar 
outros bens que lhes sejam importantes ao desenvolvimento e manutenção da vida, assumindo, assim, uma postura nitidamente utilitarista.

A preservação da natureza pelo ser humano sempre se mostrou o norte orientador da preocupação com a Terra, repercutindo nos textos legislativos, inclusive na Constituição Federal de 1988 que, ao desenhar uma proposta de Estado de Direito Socioambiental, o fez numa perspectiva antropocêntrica, dispondo que "[...] todos têm direito ao meio ambiente ecologicamente equilibrado, bem de uso comum do povo e essencial à sadia qualidade de vida", consoante previsto no artigo 225.

Limitar a proteção ambiental ao ser humano, interpretação restritiva, não deve ser a atitude mais coerente a ser adotada no estágio em que se encontram os estudos e a dialética e holística interação de todos os seres. Não tem sido outro o caminho percorrido pelas cortes no Brasil, mas um extenso percurso foi trilhado até se aportar a estas novas elaborações do conhecimento.

A formulação do biocentrismo não significou a substituição do antropocentrismo, ao invés, fincou suas premissas em alicerces já estabelecidos por este, num movimento dialético e não de superação (NALINI, 2015). Agregam-se, no Direito, a uma proteção já reconhecida a valores que trarão norte à interpretação das normas que tutelam direta ou indiretamente o meio ambiente.

A preocupação com o meio ambiente espraiou-se para uma responsabilidade não apenas do ente da Representação Estatal, mas de toda a coletividade (MORATO, 2000). Vive-se este "despertar ecológico" desde o final dos anos de 1960, fazendo-se sentir no plano internacional com repercussões no Direito interno dos Estados. Neste sentido, descreve Carla Amado Gomes:

Não se pretende dizer que o século XX tenha sido até aí um deserto no que tange à tutela do ambiente - há algumas convenções internacionais celebradas logo no princípio do século que visam a protecção das focas, ou a preservação de certas espécies cinegéticas africanas. Contudo, a sua vocação é utilitarista e a sua técnica revela-se assistemática. (GOMES, 2018, p. 23).

Mostra-se imprescindível uma mudança comportamental humana perante o meio ambiente, pois, de uma posição meramente utilitarista, passa-se a sentir a necessidade de preservá-la como valor em si. Fala-se, ainda, em um "antropocentrismo mitigado", que

[...] autoriza uma visão mais holística quando da tutela da fauna, pois admite a extensão da proteção jurídica ao meio ambiente não só em decorrência dos interesses do ser humano e de suas futuras geraç̃oes, mas também inclui o meio ambiente natural como 
bem jurídico autônomo, dotado de valor próprio, buscando assim harmonizar a relação entre este e a natureza não humana. (PADILHA, 2010, p. 372).

Há, com isso, uma relativização de conceitos que se pretendem absolutos, como o de soberania entre os Estados, que buscam desenhar um modelo de corresponsabilidade pelo futuro da Terra. Nem sempre, entretanto, fora assim, pois “[...] a visão mecanicista da propriedade e da soberania é responsável pela situação dramática em que se encontra o nosso planeta". (CAPRA, 2018).

\section{A função do Direito Penal na tutela da vida não humana: o problema dos maus-tratos contra os animais}

Para que o Direito Penal tutele um bem jurídico, há que se mostrar a importância do bem e justificar a necessidade de proteção por esse ramo, considerado de ultima ratio, ou seja, só chamado quando os demais não conseguem, de maneira satisfatória, resolver a situação. Neste sentido, o próprio conceito de bem jurídico é de delimitação difícil, cuja eleição demanda um esforço interpretativo acerca da relevância do que se pretende tutelar.

Algumas indagações, com efeito, são procedidas: quais são esses bens mais relevantes? Quem determina a escolha qualitativa de tais bens? Quais são os critérios a serem atendidos para a eleição de um bem como passível de proteção penal?

Mostrando a complexidade temática, esclarece Luiz Régis Prado que, “[...] apesar de o postulado de que o delito lesa ou ameaça de lesão os bens jurídicos ter a concordância quase total e pacífica dos doutrinadores, o mesmo não se pode dizer a respeito do conceito de bem jurídico, onde reina grande controvérsia". (PRADO, 2003, p. 35-36).

Os maus-tratos contra os animais conformam um tema que aufere importância a cada dia, causando grande repercussão quando são noticiadas situações envolvendo o uso de violência desmedida. Há intensivo clamor social na repressão e punição dessas condutas, encontrando eco na legislação penal, que busca coibir tais práticas ${ }^{3}$.

\footnotetext{
${ }^{3}$ Muitas são as notícias veiculadas na imprensa envolvendo maus tratos aos animais. Mencionamos duas: "A Polícia Civil localizou em Itu (SP) uma chácara com 33 cachorros da raça pitbull na tarde desta segunda-feira, 16. O proprietário do local é um dos 41 presos que participavam de uma rinha de cães em Mairiporã, na região metropolitana da capital". (ROMANO, Giovanna. Polícia encontra 33 pitbulls em chácara de preso em rinha de cães. Disponível em: https://veja.abril.com.br/brasil/policia-encontra-33-pitbulls-em-chacara-de-preso-em-rinha-
} 
Infligir maus-tratos ou a morte de um animal foi outrora considerado um ilícito causador de dano de natureza patrimonial para o proprietário, quando se tinha a coisificação dos seres não humanos, considerados bens integrantes do patrimônio da vítima.

Para o Direito Civil, os bens são valores materiais e imateriais que compreendem as coisas, que podem ser corpóreas ou incorpóreas, havendo quem elenque, nestas últimas, a própria dignidade, sendo possível extrair essa interpretação do próprio conceito de bem oferecido por Pontes de Miranda ${ }^{4}$.

A superação do entendimento de que os animais são bens ou coisas passa ainda pelo Direito Civil que, tradicionalmente, concebe a ideia de bem associada a sua utilidade e raridade, somando-se, ainda, aos requisitos da patrimonialidade e a susceptibilidade de apropriação - os últimos também não unânimes na doutrina. Críticas são feitas à historicidade que acompanha o conceito de "útil" e, tampouco, este atributo é exigido no século XXI, restando superados também todos os outros requisitos (CHAVES, 2017).

Ademais, o Direito Ambiental, reconhecido como ramo autônomo, porém correlacionado a outros, como dialeticamente o é o Direito, acentuou a "descoisificação" da natureza e dos seus principais componentes.

Chamando à colação as conclusões da doutrina civilista, percebe-se que "[...] não se aceita, atualmente, que os animais sejam equiparados aos demais bens - como os minerais, por exemplo. O bem-estar desses animais passa a ser item relevante da pauta". (CHAVES, 2017, p. 440).

clandestina/. Acesso em: 01.05.2020). Outra matéria mostra que até os órgãos encarregados de fiscalização envolvem-se em situações que podem configurar maus tratos. Veja-se o caso ocorrido em Fortaleza: "Após cair de um veículo da Autarquia Municipal do Meio Ambiente e Controle Urbano (AMMA), um cachorro da raça pitbull foi arrastado pelo automóvel preso em uma corda. A cena foi flagrada por pessoas que transitavam pelo Eusébio, Região Metropolitana de Fortaleza (...) Imagens também mostraram o cachorro amarrado e, aparentemente, com dificuldade de respirar. Um vídeo gravado pelos responsáveis mostra o cão e afirma que ele caiu durante o trajeto, após ser apreendido. No vídeo, os homens afirmam que o animal foi retirado [...] da residência após atacar uma família e que houve dificuldade para colocá-lo na carroceria de um automóvel". (SISNANDO, Jéssika. Cachorro é arrastado preso à carroceria de automóvel de proteção ambiental do Eusébio. Disponível em: https://www.opovo.com.br/noticias/ceara/eusebio/2020/03/17/cachorro-e-arrastado-preso-a-carroceria-deautomovel-de-protecao-ambiental-do-eusebio.html. Acesso em: 30.04.2020).

${ }^{4}$ Destacava que o objeto de direito é "[...] algum bem da vida que pode ser elemento do suporte fáctico de alguma regra jurídica, de cuja incidência emane fato jurídico, produtor de direito". (PONTES DE MIRANDA. Tratado de Direito Privado. T.II. Rio de Janeiro: Borsoi, 1954, p. 22). 
In alia manu, assevera o mesmo autor que "[...] reconhecer que os seres da natureza ostentam um status próprio, peculiar e diferenciado, não significa reconhecer-lhes como sujeitos de direitos, apenas que não podemos indistintamente coisificar a natureza". (IBIDEM, p. 440).

Para o Direito Civil mais moderno, animais não são coisas, tampouco são sujeitos de direito, como já reconhecido em ordens jurídicas alienígenas. Caminha-se, portanto, para uma posição intermediária, levando em consideração estudos que comprovam tratar-se de seres sencientes, ou seja, à semelhança dos humanos, também são capazes de “[...] vivenciar sentimentos como dor, angústia, solidão, amor, alegria e raiva" ${ }^{\circ}$.

O Senado Federal aprovou, em 07 de agosto de 2019, o Projeto de Lei da Câmara ${ }^{\circ} 27$, de 2018, reconhecendo que "[...] os animais não humanos possuem natureza jurídica sui generis e são sujeitos de direitos despersonificados, dos quais devem gozar e obter tutela jurisdicional em caso de violação, vedado o seu tratamento como coisa". Referido projeto visa a acrescentar dispositivo à Lei 9.605/98, concluindo que

\begin{abstract}
Os animais não humanos possuem natureza jurídica sui generis e são sujeitos com direitos despersonificados, dos quais devem gozar e, em caso de violação, obter tutela jurisdicional, vedado o seu tratamento como coisa.

Parágrafo único. A tutela jurisdicional referida no caput não se aplica ao uso e à disposição dos animais empregados na produção agropecuária e na pesquisa científica nem aos animais que participam de manifestações culturais registradas como bem de natureza imaterial integrante do patrimônio cultural brasileiro, resguardada a sua dignidade ${ }^{6}$.
\end{abstract}

Quanto ao parágrafo único, conforme redação aprovada pelo Senado Federal, quando da abordagem da interpretação legal e das decisões judiciais, serão verificadas as limitações a sua aplicação.

Vale lembrar, ainda, que, de acordo com Kant, o universo 'não humano' está contido no “[...] conceito de coisas, e, portanto, não de pessoas, tendo apenas um valor relativo, na medida em que prestariam - em maior ou menor grau - como 'meio' para a satisfação da vontade humana”. (SARLET, 2011, p. 63). Consagra-se, com efeito, uma visão meramente antropocêntrica de natureza, prestando-se à realização dos desejos e necessidades humanas.

\footnotetext{
5 Disponível em: http://www.sema.df.gov.br/lei-proibe-utilizacao-de-animais-em-circos-e-espetaculos-no-distritofederal/. Acesso em: 02.04.2020.

${ }^{6}$ SENADO FEDERAL. PARECER No 198, DE 2019 - PLEN/SF. Redação final da Emenda do Senado ao Projeto de Lei da Câmara $\mathrm{n}^{\circ}$ 27, de 2018 ( $\mathrm{n}^{\circ}$ 6.799, de 2013, na Casa de origem). Disponível em: https://legis.senado.leg.br/sdleg-getter/documento?dm=7987790\&ts=1574367803486\&disposition=inline. Acesso em: 04.04.2020.
} 
É possível que a necessidade de repensar a natureza jurídica dos animais tenha impulsionado o legislador a inserir na Lei das Contravenções Penais o artigo 64, dispondo sobre a crueldade contra animais, estabelecendo que

Art. 64. Tratar animal com crueldade ou submetê-lo a trabalho excessivo:

Pena - prisão simples, de dez dias a um mês, ou multa, de cem a quinhentos mil réis.

$\S 1^{\circ} \mathrm{Na}$ mesma pena incorre aquele que, embora para fins didáticos ou científicos, realiza em lugar público ou exposto ao público, experiência dolorosa ou cruel em animal vivo.

$\S 2^{\circ}$ Aplica-se a pena com aumento de metade, se o animal é submetido a trabalho excessivo ou tratado com crueldade, em exibição ou espetáculo público.

Naquele momento, as interpretações conferidas ao dispositivo citado entendiam que o tipo não demandaria um dolo específico de maltratar “[...] por malignidade ou para deleitar-se dos seus sofrimentos. Basta a voluntariedade do ato, que encerra um tratamento cruel”"7. Urge observar, entretanto, que, na referida contravenção, o sujeito passivo, ou seja, a vítima, era o próprio Estado, não o proprietário do animal e tampouco este último, sofredor das consequências diretas da conduta ${ }^{8}$.

É interessante observar, pela leitura dos julgados da época, que as decisões distinguiam situações em que o animal "provocava" a resposta agressiva, descaracterizando os maus-tratos, sem ponderar a proporcionalidade dos usos necessários, daquelas em que o animal sofria um ataque sendo "inocente". Veja-se:

Acusado que repele invasão à sua propriedade, atirando contra carneiro que nela adentrava - ausência de intenção de lhe causar maus tratos - se o acusado não quis infringir maus tratos, mas defender a sua propriedade contra os animais que a invadiam, não tem como configurar a contravenção do art. 64 da respectiva lei ${ }^{9}$.

\footnotetext{
${ }^{7}$ Decisão extraída do julgamento proferido pelo TACRIM, SP - AC - Rel. Minhoto Júnior - $R T$ 222/363. Disponível em: FRANCO, Alberto Silva et al. Leis Penais Especiais e sua Interpretação Jurisprudencial. São Paulo: Editora Revista dos Tribunais, 1995, p. 283.

${ }^{8}$ Assim manifestou-se o Tribunal de Justiça do Estado de São Paulo, ao entender que, “[...] no artigo 64 da LCP o ofendido é o Estado e não o proprietário do animal, pois o que a lei tutela, no dispositivo em apreço, é o sentimento ético-social de humanidade para com os animais". (TACRIM, SP - Rel. Adriano Marrey - RT 211/390. Disponível em: FRANCO, Alberto Silva et al. Leis Penais Especiais e sua Interpretação Jurisprudencial. São Paulo: Editora Revista dos Tribunais, 1995, p. 284).

${ }^{9}$ Decisão extraída do julgamento proferido pelo JURICRIM - Franceschini, n. 1.956-A. Disponível em: FRANCO, Alberto Silva $e t$ al. Leis Penais Especiais e sua Interpretação Jurisprudencial. São Paulo: Editora Revista dos Tribunais, 1995, p. 285.
} 
Em outro sentido, tem-se que "[...] caracteriza a contravenção do art. 64 da competente lei, ministrar substância venenosa a animal inofensivo, causando-lhe sofrimento e morte" ${ }^{\prime 10}$. No mesmo senso, lê-se que “[...] quem se vê atacado por um cão tem relevante motivo para sacrificá-lo, mesmo a tiros, pois, nas circunstâncias, o meio usado é necessário"11.

Superando a mera patrimonialização dos animais, assim como das consequências da violência por eles sofridas, o Direito Penal, no artigo 32 da Lei 9.605/98 ${ }^{12}$, alçou à condição de crime o que outrora era uma contravenção penal, revogando tacitamente o artigo 64 mencionado em passagem anterior. Tipificou a conduta de "[...] praticar ato de abuso, maus-tratos, ferir ou mutilar animais silvestres, domésticos ou domesticados, nativos ou exóticos”, cuja pena é de detenção, de três meses a um ano, e multa.

Portanto, o crime de maus-tratos, compreendendo a mutilação e os ferimentos causados aos animais, visa a proteção da fauna silvestre, doméstica ou domesticada, nativa ou exótica. Há quem defenda o ponto de vista de que, quanto à tutela dos animais domésticos, esta deveria ser feita por intermédio do Direito Administrativo sancionador ou, no máximo, pela Lei das Contravenções Penais (PRADO, 2013, p. 199).

Luiz Régis Prado chama a atenção, ainda, para o fato de que a tutela do meio ambiente por via do tipo penal há momentos citado, faz-se somente de maneira transversal, pois o objetivo primário da proteção é o "legítimo sentimento de humanidade", exteriorizado por intermédio de atos de piedade e compaixão para com os animais (PRADO, 2013, p. 199). Observa-se que o sujeito passivo ou vítima do delito não é o animal, mas sim a coletividade, sendo este apenas o objeto jurídico, ou seja, aquele sobre o qual recai a conduta criminosa.

Variadas são as modalidades de exposição dos animais aos maus-tratos, por exemplo, violência física, privação de alimentos, submissão a trabalhos excessivos, entre outras. Uma prática que era bastante comum e aceita socialmente consistia no treinamento de animais para atividades circenses, mediante o uso de violência física, o que vem sendo coibido.

\footnotetext{
${ }^{10}$ Decisão extraída do julgamento proferido pelo TACRIM, SP - RHC - Rel. Albano Nogueira - JUTACRIM 55/16. Disponível em: FRANCO, Alberto Silva et al. Leis Penais Especiais e sua Interpretação Jurisprudencial. São Paulo: Editora Revista dos Tribunais, 1995, p. 285.

${ }^{11}$ Decisão extraída do julgamento proferido pelo TACRIM, SP - AC - Rel. Lauro Alves - JURICRIM 55/287. Disponível em: FRANCO, Alberto Silva et al. Leis Penais Especiais e sua Interpretação Jurisprudencial. São Paulo: Editora Revista dos Tribunais, 1995, p. 286.

${ }^{12} \mathrm{O}$ artigo 32 da Lei 9.605/98 dispõe ainda de dois parágrafos, quais sejam: $\S 1^{\circ}$ Incorre nas mesmas penas quem realiza experiência dolorosa ou cruel em animal vivo, ainda que para fins didáticos ou científicos, quando existirem recursos alternativos. $\S 2^{\circ}$ A pena é aumentada de um sexto a um terço, se ocorre morte do animal.
} 
Menciona-se o Estado de São Paulo, com a aprovação do Código de Proteção aos Animais (Lei 11.977/2005) ${ }^{13}$, que traz em dois dispositivos importantes avanços na proteção dos animais:

Artigo 20 - É vedado realizar ou promover lutas entre animais da mesma espécie ou de espécies diferentes, touradas, simulacros de tourada e vaquejadas, em locais públicos e privados.

Artigo 21 - É vedada a apresentação ou utilização de animais em espetáculos circenses.

O Distrito Federal, na mesma linha, aprovou, mais recentemente, a Lei 6.113/2018, proibindo a apresentação e a utilização de animais domésticos e da fauna silvestre nativos ou exóticos em espetáculos circenses ou outros congêneres. Ao explicar a fundamentação da lei, observou-se que está baseada no "Princípio das Cinco Liberdades"14 para a promoção do bemestar dos animais, quais sejam:

1. Estar livre de fome e sede;

2. estar livre de desconforto;

3. estar livre de doença e injúria;

4. ter liberdade para expressar os comportamentos naturais da espécie; e

5. estar livre de medo e de estresse.

Visando a garantir a proteção dos animais, a Lei 11.794, de 8 de outubro de 2008, estabelece procedimentos para o uso científico de animais, regulamentando o inciso VII do § 1o do art. 225 da Constituição Federal ${ }^{15}$, prevalecendo que sempre que existirem opções ao uso de animais estas deverão ser priorizadas.

Há, ainda, um movimento para recrudescimento da legislação que trata do crime de maus-tratos contra animais e que poderá ser objeto de alteração pelo Projeto de Lei 1095/19, já aprovado no Plenário da Câmara dos Deputados ${ }^{16}$, na data de 17 de dezembro de 2019, seguindo

$\begin{array}{ll}13 & \text { Disponível } \\ \text { http } / / \text { dobuscadireta imprensaoficial com } \mathrm{br} / \text { default aspx?DataPub }\end{array}$

em:

http://dobuscadireta.imprensaoficial.com.br/default.aspx?DataPublicacao=20050826\&Caderno=DOE-

I\&NumeroPagina=3. Acesso em: 02.04.2020.

14 Disponível em: http://www.sema.df.gov.br/lei-proibe-utilizacao-de-animais-em-circos-e-espetaculos-no-distritofederal/. Acesso em: 02.04.2020.

${ }^{15} \mathrm{O}$ dispositivo estabelece que incumbe ao Poder Público "VII - proteger a fauna e a flora, vedadas, na forma da lei, as práticas que coloquem em risco sua função ecológica, provoquem a extinção de espécies ou submetam os animais a crueldade".

${ }^{16}$ O Projeto de Lei 1095/2019 traz como exemplo em sua justificativa o caso ocorrido em Osasco, São Paulo, quando um cachorro foi brutalmente morto, após ter sido espancado e envenenado por um segurança do Supermercado Carrefour, fato ocorrido no dia 28 de novembro de 2018. Disponível em: https://www.camara.leg.br/proposicoesWeb/prop_mostrarintegra;jsessionid=D1AC92A9D8F1B5927F0AD768C0A D5706.proposicoesWebExterno2?codteor=1714454\&filename=PL+1095/2019. Acesso em 19.12.2019. 
para votação no Senado. Prevê pena de reclusão de dois a cinco anos e multa (configurando uma novatio legis in pejus, ou seja, uma lei para pior ${ }^{17}$, alterando a sanção que era de detenção e passará a ser de reclusão.

No Anteprojeto do Novo Código Penal (Projeto de Lei do Senado ${ }^{\circ} 236$, de $2012^{18}$ ), o artigo 391 insere no rol dos crimes contra interesses metaindividuais a conduta de "Praticar ato de abuso ou maus-tratos, a animais, domésticos, domesticados ou silvestres, nativos ou exóticos”, punindo com prisão de um a quatro anos.

\section{A elaboração jurisprudencial no reconhecimento da dignidade da vida não humana}

Um dos grandes problemas debatidos no âmbito judicial, assim como do legislativo, consiste na análise da realização das vaquejadas. Oriundas dos sertões nordestinos, remontam a um passado distante, havendo relatos da prática desde os séculos XVII e XVIII (CASCUDO, 1976). Consiste numa “[...] prática esportiva, cultural, inertemente cruel (...) em que dois vaqueiros trabalham em sincronia para derrubar o boi dentro de uma marca específica num campo de areia" ${ }^{, 19}$.

Iniciada como uma consequência da busca do gado, tornou-se uma atividade comercial rentável, mediante a exposição das habilidades dos peões, tornando-se um espetáculo com público pagante e a premiação dos melhores vaqueiros. Com isso, os Estados-membros passaram a disciplinar a prática que incentiva o turismo e traz ganhos também aos cofres públicos, descurando da preocupação com a integridade do animal.

No julgamento da ADI 4983, adiante analisada, o Supremo Tribunal Federal reconhece que a vaquejada, prática considerada esportiva e cultural no Nordeste do Brasil, modificou-se com o tempo, passando da "[...] antiga necessidade de os fazendeiros reunirem o gado, e a

\footnotetext{
${ }^{17}$ A diferença entre uma novatio legis incriminadora e uma novatio legis in pejus reside no fato de que no primeiro caso a norma não existia e agora passa a criminalizar a conduta, enquanto que, na segunda situação, já há o crime que vem a receber tratamento penal mais rigoroso.

${ }^{18}$ Consta no site do Senado como última tramitação do Anteprojeto do Novo Código Penal sua estada na Comissão de Constituição, Justiça e Cidadania (Secretaria de Apoio à Comissão de Constituição, Justiça e Cidadania), com relatoria do senador Rodrigo Pacheco (07.02.2020). Disponível em: https://www25.senado.leg.br/web/atividade/materias/-/materia/106404.

19 Disponível em: https://ambitojuridico.com.br/cadernos/direito-ambiental/vaquejada-a-contradicao-daconstituicao-em-relacao-a-proibicao-desta-pratica/. Acesso em: 02.04.2020.
} 
transformação, com o tempo, em espetáculo esportivo altamente lucrativo, movimentando cerca de R\$ 14 milhões por ano". 20

O Estado do Ceará, pela Lei estadual $n^{\circ} 15.299 / 2013$, regulamentou a vaquejada como atividade desportiva e cultural, conceituando- a como "[...] todo evento de natureza competitiva, no qual uma dupla de vaqueiro a cavalo persegue animal bovino, objetivando dominá-lo"21. Dispõe o artigo $4^{\circ}, \S 3^{\circ}$ da lei estadual, que "O vaqueiro que, por motivo injustificado, se exceder no trato com o animal, ferindo-o ou maltratando-o de forma intencional, deverá ser excluído da prova" $^{22}$.

Contra a citada lei, foi ajuizada ação direta de inconstitucionalidade pela Procuradoria Geral da República (ADI 4983), de relatoria do ministro Marco Aurélio. Em conflito: a proteção constitucional do meio ambiente versus os valores culturais da atividade desportiva, conforme previsto no artigo 215 da Constituição Federal de $1988^{23}$, mediante a técnica da ponderação. Buscou, ainda, o Supremo Tribunal Federal preencher, por análise de laudos técnicos, o conceito de "crueldade" 24 , previsto no inciso VII do parágrafo $1^{\circ}$ do artigo 225 da Constituição Federal.

Já existiam precedentes no Supremo Tribunal Federal pela não recepção de práticas cruentas contra os animas, como, por exemplo, a "briga de galos", por via da ADI 1.856/RJ, relator ministro Celso de Mello, julgada em 26 de maio de 2011, e ADI 2.514/SC, relator ministro Eros Grau, apreciada em 29 de junho de 2005. A "farra do boi" também fora apreciada pela Corte Suprema por intermédio do Recurso Extraordinário $\mathrm{n}^{\circ} 153.531 / \mathrm{SC}$, relator ministro Francisco Rezek, de 3 de junho de 1997.

Ao final do julgamento da ADI 4983, concluiu o relator, ministro Marco Aurélio, que

\footnotetext{
${ }^{20}$ SUPREMO TRIBUNAL FEDERAL. ADI 4983/CE. Disponível em: http://www.stf.jus.br/arquivo/cms/noticiaNoticiaStf/anexo/ADI4983relator.pdf. Acesso em: 06.04.2020.

${ }^{21}$ Lei $N^{\circ} 15299$ DE 08/01/2013. Artigo 2. Disponível em: https://www.legisweb.com.br/legislacao/?id=250070. Acesso em: 06.04.2020.

${ }^{22}$ Lei No 15299 DE 08/01/2013. Artigo 2º . Disponível em: https://www.legisweb.com.br/legislacao/?id=250070. Acesso em: 06.04.2020.

${ }^{23}$ Dispõe o caput do artigo 215 da Constituição Federal que "O Estado garantirá a todos o pleno exercício dos direitos culturais e acesso às fontes da cultura nacional, e apoiará e incentivará a valorização e a difusão das manifestações culturais".

${ }^{24} \mathrm{O}$ Procurador Geral da República juntou à ADI referida laudos técnicos comprovando os malefícios da prática para a saúde do animal, podendo resultar em “[...] fraturas nas patas, ruptura dos ligamentos e dos vasos sanguíneos, traumatismos e deslocamento da articulação do rabo e até seu arrancamento, do que resultam comprometimento da medula espinhal e dos nervos espinhais, dores físicas e sofrimento mental". (Disponível em: https://www.dizerodireito.com.br/2019/09/lei-138732019-altera-lei-133642016-para.html. Acesso em: 07.04.2020).
} 
O sentido da expressão "crueldade" constante da parte final do inciso VII do $\S 1^{\circ}$ do artigo 225 do Diploma Maior alcança, sem sombra de dúvida, a tortura e os maus-tratos infringidos aos bovinos durante a prática impugnada, revelando-se intolerável, a mais não poder, a conduta humana autorizada pela norma estadual atacada. No âmbito de composição dos interesses fundamentais envolvidos neste processo, há de sobressair a pretensão de proteção ao meio ambiente ${ }^{25}$.

Concluiu a Corte Excelsa que

É inconstitucional lei estadual que regulamenta a atividade da "vaquejada". Os animais envolvidos nesta prática sofrem tratamento cruel, razão pela qual esta atividade contraria o art. $225, \S 1^{\circ}$, VII, da CF/88. A crueldade provocada pela "vaquejada" faz com que, mesmo sendo esta uma atividade cultural, não possa ser permitida. A obrigação de o Estado garantir a todos o pleno exercício de direitos culturais, incentivando a valorização e a difusão das manifestações, não prescinde da observância do disposto no inciso VII do $\S 1^{\circ}$ do art. 225 da $\mathrm{CF} / 88$, que veda práticas que submetam os animais à crueldade ${ }^{26}$.

Observa-se que o julgamento não foi unânime, pois o placar final foi de 6x5, dando a dimensão da importância da discussão que envolve a matéria. Seguiram o relator os ministros Luís Roberto Barroso, Rosa Weber, Ricardo Lewandowski, Celso de Mello e a ministra Cármen Lúcia. Em sentido contrário, restaram vencidos os ministros Edson Fachin, Teori Zavascki, Luiz Fux, Dias Toffoli e Gilmar Mendes.

O ministro Dias Toffoli, posicionando-se pela constitucionalidade da lei estadual, manifestou-se ponderando que “[...] vejo com clareza solar que essa é uma atividade esportiva e festiva, que pertence à cultura do povo, portanto há de ser preservada"27.

Situação interessante ocorreu cerca de um mês após a decisão acima proferida pelo Supremo Tribunal Federal, quando o Congresso Nacional editou a Lei $n^{\circ} 13.364$, de 29 de novembro de 2016, reconhecendo no artigo $1^{\circ}$

[...] o rodeio, a vaquejada e o laço, bem como as respectivas expressões artísticas e esportivas, como manifestações culturais nacionais, eleva essas atividades à condição de bens de natureza imaterial integrantes do patrimônio cultural brasileiro e dispõe sobre as modalidades esportivas equestres tradicionais e sobre a proteção ao bem-estar animal.

Prossegue no artigo $2^{\circ}$, dispondo que

[...] o rodeio, a vaquejada e o laço, bem como as respectivas expressões artísticas e esportivas, são reconhecidos como manifestações culturais nacionais e elevados à

\footnotetext{
${ }^{25}$ SUPREMO TRIBUNAL FEDERAL. ADI 4983/CE. Disponível em: http://www.stf.jus.br/arquivo/cms/noticiaNoticiaStf/anexo/ADI4983relator.pdf. Acesso em: 06.04.2020.

${ }^{26}$ STF. Plenário. ADI 4983/CE, Rel. Min. Marco Aurélio, julgado em 06/10/2016 (Info 842). Disponível em: http://www.stf.jus.br/arquivo/informativo/documento/informativo842.htm. Acesso em: 07.04.2020.

27 Disponível em: http://www.stf.jus.br/portal/cms/verNoticiaDetalhe.asp?idConteudo=326838. Acesso em: 06.04.2020.
} 
condição de bens de natureza imaterial integrantes do patrimônio cultural brasileiro, enquanto atividades intrinsecamente ligadas à vida, à identidade, à ação e à memória de grupos formadores da sociedade brasileira.

$\mathrm{Na}$ redação originária previa a lei apenas a vaquejada, recebendo acréscimo da Lei 13.873, de 17 de setembro de 2019, para nela incluir as atividades de laço.

Constitui-se um movimento em sentido contrário à decisão tomada pelo Supremo Tribunal Federal, uma verdadeira "reação" do Poder Legislativo, na adoção do que se chama de "ativismo congressual" ou "reversão jurisprudencial". Legítima quanto ao formato, pois a manifestação da Corte deu-se em relação a uma lei estadual específica. Neste imbróglio, aflorou a Emenda Constitucional número 96, de 06 de junho de 2017, acrescentando ao artigo 225 da Constituição Federal, o $\S 7^{\circ}$, com o seguinte teor:

Para fins do disposto na parte final do inciso VII do $\S 1^{\circ}$ deste artigo, não se consideram cruéis as práticas desportivas que utilizem animais, desde que sejam manifestações culturais, conforme o $\S 1^{\circ}$ do art. 215 desta Constituição Federal, registradas como bem de natureza imaterial integrante do patrimônio cultural brasileiro, devendo ser regulamentadas por lei específica que assegure o bem-estar dos animais envolvidos

Portanto, a despeito de movimentos em sentido contrário, enfraquecendo a proteção do meio ambiente, é nítida a percepção de que os juízes e tribunais brasileiros vêm paulatinamente construindo alicerces para o desenvolvimento de uma visão direcionada para uma tutela cada vez mais integral, numa perspectiva mais coerente com as contribuições do ecocentrismo.

Tal incursão do legislador, aprovando leis que diminuem a proteção do meio, configuram situações gritantes de um reprovável retrocesso na proteção ambiental, de conteúdo nitidamente inconstitucional, capaz de fazer repensar como legítima a constitucionalidade de normas introduzidas por emendas ao Texto Constitucional. Há que se analisar, ainda, os efeitos de uma lei declarada inconstitucional e seus efeitos vinculativos.

Em importante decisão, símbolo do reconhecimento e case a orientar novas discussões sobre o assunto, assentou o Superior Tribunal de Justiça, no julgamento do Recurso Especial 1.797.175/SP, da $2^{\text {a }}$ Turma e relatoria do ministro Og Fernandes, em 13 de maio de 2019, no qual se discutiu a "posse" de um "papagaio-verdadeiro" que

[...] a retirada do animal silvestre depois de largo período de domesticação implica, inclusive, violação dos direitos do próprio animal. No ponto, destaca-se, como premissa de raciocínio, que a abordagem ecológica da legislação brasileira justifica-se em razão da importância que a qualidade, o equilíbrio e a segurança ambiental têm para o desfrute, a tutela e a promoção dos direitos fundamentais. O viés ecológico do tratamento a ser dispensado ao tema decorre da degradação perpetrada pela ação 
humana no meio natural, dado que os efeitos negativos de tais práticas resultam, na maioria das vezes, em violação direta ou mesmo indireta dos direitos fundamentais ${ }^{28}$.

O Superior Tribunal de Justiça esboça entendimentos pelo reconhecimento da existência de uma dimensão ecológica da dignidade, no que chamou no julgamento do Recurso Especial outrora citado de "[...] violação da dimensão ecológica do princípio da dignidade da pessoa humana", fortalecendo a existência de um regime jurídico dos animais não humanos (SARLET; FENSTERSIFER, online $)^{29}$.

No julgamento do Recurso Especial 667.867/SP, 2 ${ }^{\mathrm{a}}$ Turma, o ministro Og Fernantes, destacou:

[...] faz-se necessário [...] repensar a concepção kantiniana individualista e antropocêntrica de dignidade e avançar rumo a uma compreensão ecológica da dignidade da pessoa e da vida em geral, considerando a premissão de que a matriz filosófica moderna para a concepção de dignidade (da pessoa humana) radica essencialmente no pensamento kantiniano ${ }^{30}$.

O conteúdo do princípio da dignidade adquire contornos cada vez mais ampliativos, englobando no tempo atual uma dimensão de proteção em ultrapasse à preocupação com a segurança e bem-estar dos seres humanos, conferindo à tutela dos animais o resguardo necessário a sua integridade física e psíquica, uma vez entendidos como seres sencientes.

\section{Conclusão}

A pesquisa relatoriada por intermédio deste texto mostra o evoluir da proteção do meio ambiente, não por meio do histórico conferido pelo lento processo de incorporação das convenções e feituras de leis internas disciplinando o assunto, mas, sim, analisando a mudança de paradigma que se mostrou como o caminho único possível na preservação ambiental.

Passa-se de uma visão eminentemente antropocêntrica, alçando o homem como centro em torno do qual gravitam as demais preocupações com o meio ambiente, posição esta que

\footnotetext{
${ }^{28}$ BRASIL. Superior Tribunal de Justiça. REsp 667.867/SP, 2 ${ }^{\mathrm{a}}$ Turma, el. Min. Og Fernantes, j. 17.10.2018. Disponível no endereço eletrônico: https://ww2.stj.jus.br/processo/pesquisa/?termo=+REsp+1.797.175\&aplicacao=processos.ea\&tipoPesquisa=tipoPes quisaGenerica\&chkordem=DESC\&chkMorto=MORTO. Acesso em 22.11.2019.

${ }^{29}$ Disponível em: https://www.conjur.com.br/2019-mai-10/direitos-fundamentais-stj-dimensao-ecologica-dignidadedireitos-animal-nao-humano. Acesso em 08.04.2020.

${ }^{30}$ BRASIL. Superior Tribunal de Justiça. REsp 667.867/SP, $2^{\text {a }}$ Turma, el. Min. Og Fernantes, j. 17.10.2018. Disponível no endereço eletrônico: https://ww2.stj.jus.br/processo/pesquisa/?termo=+REsp+1.797.175\&aplicacao=processos.ea\&tipoPesquisa=tipoPes quisaGenerica\&chkordem=DESC\&chkMorto=MORTO. Acesso em 08.04.2020.
} 
repercutiu inclusive, no texto da atual Constituição brasileira, para uma tomada de rumos calcada agora numa maior preocupação com o próprio ambiente, mais condizente com os valores trabalhados pelo ecocentrismo.

Em tais circunstâncias, um dos temas que aufere destaque é a importância da tutela dos animais. Para efetivar o referido ensaio, necessário se mostrou proceder-se a uma breve incursão pelo Direito Civil, especificamente, no que concerne à diferença entre coisas e bens, pois, no primeiro estádio, estavam os animais relegados a tais categorias.

Verificou-se a ocorrência de profundas alterações no trato da matéria, pois o avanço da ciência, importante aliada na compreensão dos animais, mostrou que estes, à semelhança dos humanos, possuem sentimentos, sendo inclusive capazes de exprimi-los.

Neste momento, considerados como seres sencientes, era importante rever as bases da proteção que a tutela penal dos animais permitia. De início, a conduta causadora de maus-tratos era havida como uma mera contravenção penal, apenada com maior brandura, mas o evoluir da matéria mostrou a necessidade da tipificação da conduta como crime, o que foi feito no artigo 32 da Lei 9.605/98, e, ainda assim, era pouco.

Sobra impossível dissociar, do Direito, a Sociologia, bem assim das vivências sociais, costumes e tradições, de sorte que variadas situações demandaram do Judiciário uma resposta, a exemplo das brigas de galo, da farra do boi, das vaquejadas, entre outras.

Ante tais conflitos, a ponderação se tornou a técnica mais eficaz para a solução das lides expressas. De um lado, o meio ambiente e, de outra parte, a manutenção de tradições e manifestações culturais. Acertadamente, as cortes superiores patriais decidiram que a dignidade dos seres não humanos e a injustificada colocação do animal em situação de sofrimento demostram que a decisão que privilegia a proteção integral do meio ambiente mostra-se a mais acertada.

Ainda assim, percebe-se um esforço em sentido contrário, infelizmente do próprio legislador, na aprovação de leis que, contrariando os importantes avanços alcançados via tutela jurisdicional, retrocedem no tratamento da matéria, o que se entende inconstitucional, por ser a dignidade não apenas humana, mas da vida, o fundamento axiológico em que se pauta a ordem constitucional vigente. 


\section{REFERÊNCIAS}

CAPRA, Fritjof; MATTEI, Ugo. A revolução ecojurídica: o direito sistêmico em sintonia com a natureza e a comunidade. Tradução de Jefferson Luiz Camargo. São Paulo: Cultrix, 2018.

CASCUDO, L. D. C. A vaquejada nordestina e sua origem. Natal: Fundação José Augusto, 1976.

FARIAS, Cristiano Chaves de; BRAGA NETTO, Felipe; ROSENVALD, Nelson. Manual de Direito Civil. Volume Único. Salvador: Editora JusPodivm, 2017.

FRANCO, Alberto Silva et al. Leis Penais Especiais e sua Interpretação Jurisprudencial. São Paulo: Editora Revista dos Tribunais, 1995.

GOMES, Carla Amado. Introdução ao Direito do Ambiente. 3. ed. Lisboa: AAFDL Editora, 2018.

LEITE, José Rubens Morato. Dano ambiental: do individual ao coletivo extrapatrimonial. São Paulo: Editora Revista dos Tribunais, 2000.

NALINI, José Renato. Ética Ambiental. 4. ed. São Paulo: Editora Revista dos Tribunais, 2015.

PADILHA, Norma Sueli. Fundamentos constitucionais do Direito Ambiental brasileiro. Rio de Janeiro: Elsevier, 2010.

PONTES DE MIRANDA. Tratado de Direito Privado. T.II. Rio de Janeiro: Borsoi, 1954.

PRADO, Luiz Regis. Bem jurídico- penal e Constituição. São Paulo: Editora Revista dos Tribunais, 2003.

SARLET, Ingo; FENSTERSIFER, Tiago. STJ, a dimensão ecológica da dignidade e direitos do animal não humano. Disponível em: https://www.conjur.com.br/2019-mai-10/direitosfundamentais-stj-dimensao-ecologica-dignidade-direitos-animal-nao-humano. Acesso em: 08.04.2020. 